\title{
IMPUTACIÓN CONCRETA APROXIMACIÓN RAZONABLE A LA VERDAD
}

\author{
FRANCISCO CELIS MENDOZA AYMA*
}

\begin{abstract}
Resumen
La aproximación razonable a la verdad, como presupuesto de un proceso penal constitucionalizado, requiere para su concreción que el objeto del proceso penal sea una imputación concreta que reste cualquier pretensión de realizar una justicia fuertemente intuitiva, basada en la mera sospecha, que no hacen sino desnaturalizar el carácter cognitivo del proceso penal; en línea de construir un programa de contención del poder punitivo que tenga como base la imputación concreta. Para este efecto, la imputación comprende un constructo de proposiciones fácticas estructuradas conforme a la calificación jurídica, que tengan como base los elementos de convicción, el resultado será una imputación concreta que posibilite el ejercicio real del derecho de defensa y genere el contradictorio, y por tanto, configure la esencia misma del proceso.
\end{abstract}

Palabras clave: Imputación - verdad - proceso - cognitivo - formulismo - contradictorio.

\begin{abstract}
In order to attain a reasonable belief of the truth as an assumption of a constitutionalized legal proceeding, the action must be based on specific charges that will rule out any attempt to rule on the basis of intuition alone, grounded on mere suspicion, that denaturalizes the cognitive quality of the criminal proceeding; with a view to building a program to harness the punitive power based on a specific accusation. To this effect, the accusation requires a number of factual elements structured according to their legal qualification, based on elements of certainty which will result in a specific accusation that will enable a person to exercise the right of defense, generating an adversarial proceeding, thereby configuring the very essence of the proceeding.
\end{abstract}

Key words: Accusation - truth - proceeding - cognitive - formulism adversarial.

\section{Sumario}

1. El carácter cognitivo del proceso penal. 2. Concepto. 3. Estructura de la imputación concreta. 4. Imputación y elementos de convicción. 5. La imputación concreta del dolo. 6. Operatividad funcional: Etapas. 7. Perversión de la Imputación Concreta: 8. Formulismo e imputación.

\footnotetext{
* Juez Superior Provisional de la Corte Superior de Justicia de Arequipa-Poder Judicial del Perú. Profesor de la Universidad Nacional de San Agustín, Universidad Católica de Santa María, Universidad Privada de Tacna, Universidad Nacional del Altiplano, Universidad José Carlos Mariátegui.
} 


\section{EL CARÁCTER COGNITIVO DEL PROCESO PENAL}

La reforma procesal -en su desenvolvimiento- afronta un problema central: la precariedad de las imputaciones del hecho punible, en la formalización de la investigación preparatoria y en la acusación. Los defectos que se observan son bastantes serios e inciden directamente en el objeto del debate, en la audiencia. Una precaria imputación, por ausencia o defecto de proposiciones fácticas, determina que el juicio oral ineludiblemente degenere en un debate de prejuicios, sospechas o conjeturas. Esta detestable consecuencia pervierte las audiencias en sesiones rituales de intenso reproche ético, en desmedro de su carácter cognitivo. En ese contexto, los prejuicios y las particulares conformaciones ideológicas de los juzgadores son los determinantes al momento de sentenciar. Este tipo de justicia fuertemente intuitiva, resta cualquier pretensión de aproximarse razonablemente a la verdad y hace iluso un programa de contención del poder punitivo. Esta práctica es contraria al modelo procesal cognoscitivo diseñado conforme a la Constitución.

Las características centrales de un modelo constitucional del proceso son el cognoscitivismo procesal y la estricta jurisdiccionalidad -epistemología garantista- ${ }^{1}$. El cognoscitivismo procesal exige la determinación concreta del hecho punible imputado. La imputación debe ser un hecho punible unívocamente descrito de modo que resulte susceptible de prueba y que permita su control empírico ${ }^{2}$. Este es el modelo de un proceso penal como proceso de cognición o de comprobación, que tiene como presupuesto una imputación concreta de un hecho punible, base necesaria para el desarrollo de la actividad probatoria. En efecto, este principio permite la realización de dos condiciones: la verificabilidad o refutabilidad de la hipótesis acusatoria y su prueba empírica; y, en consecuencia el fundamento de la sentencia ${ }^{3}$, dado que la determinación concreta de la imputación de un hecho punible afecta de manera decidida los fundamentos de hecho y de derecho con lo que el juez justifica sus decisiones ${ }^{4}$.

\footnotetext{
1 Ello no significa que las otras características de la epistemología garantista, esto es el convencionalismo penal y la estricta legalidad no sean importantes, claro que lo son, pues son el presupuesto del cognoscitivismo procesal.

2 El Tribunal Constitucional en reiterada jurisprudencia ha puesto énfasis en señalar que "la acusación ha de ser cierta, no implícita, sino precisa, clara y expresa". Véase Exp. 8123-2005-PH/TC. Exp. 7357-2006-PHC/ TC.

3 "Es necesario que en el proceso exista una imputación concreta; en especial, que el juicio se fundamente sobre una acusación precisa y detallada, que sirva de límite al ámbito de decisión del tribunal" (BINDER, Alberto. Introducción al Derecho Procesal Penal. Buenos Aires: Ad-Hoc, 1993, p.161).

4 FERRAJOLI, Luigi. Derecho y Razón. Madrid: Editorial Trotta, 1995, pp. 36 y 37.
} 
El principio acusatorio tiene como base la separación entre acusador y juez; presupone la diferenciación entre los sujetos que acusan, los que controlan la acusación y los que juzgan; una cosa es la atribución de imputar y otra, la de juzgar. Este principio representa la condición esencial de la imparcialidad del juez respecto a las partes de la causa y también el presupuesto de la carga de la imputación ${ }^{5}$. No obstante, esta distribución de roles es inútil si la fiscalía no imputa concretamente un hecho punible definido y el juez de control de acusación no realiza su función. En ese sentido, el principio acusatorio nunca podrá tener realización, dado que la imputación concreta es la piedra angular que delimita el objeto del proceso; si no hay imputación concreta no hay materialización del principio acusatorio.

Ciertamente al Ministerio Público le corresponde delimitar la imputación concreta -aspecto principal de la contradicción-. Pero en la dinámica del proceso, su propia dialéctica genera un espacio para que la defensa (el contradictor) configure el objeto del debate. Así analíticamente la defensa de manera razonable podrá señalar -considerando los hechos imposibles de cambiar- convenciones sobre determinadas proposiciones fácticas; con ello focaliza el debate. En este sentido, la concreción de la imputación permitirá fijar un blanco que oriente óptimamente la actividad defensiva del imputado.

La imputación concreta debe ser definida y configurada para posibilitar el ejercicio real del derecho de defensa materializando una resistencia idónea ${ }^{6}$. Es el presupuesto necesario de la garantía - principio del contradictorio, en efecto, no es posible materializar un contradictorio si no se tiene una imputación concreta. El imputado sólo puede defenderse de una imputación definida. El derecho de defensa se enerva sino existe imputación concreta y definida susceptible de control ${ }^{7}$. Si las proposiciones fácticas de la imputación no están definidas simplemente no se genera una contradicción entre pretensión y oposición. Solo desde esta perspectiva se comprende porque el objeto del

\footnotetext{
5 Es contundente lo señalado por el maestro Montero Aroca: “No puede haber proceso si no hay acusación y ésta ha de ser formulada por persona distinta de quién ha de juzgar: Estamos ante algo tan obvio, pues no existe verdadero proceso si se confunden los papeles de juez y de acusador..." (MONTERO AROCA, Juan. Principios del Proceso Penal. Valencia: Editorial Tirant Lo Blanch alternativa, 1997, p. 96).

6 En ese orden de ideas San Martín Castro, afirma: "Como quiera que el objeto del proceso penal está conformado por un hecho (acción u omisión), es pues, necesario e imprescindible que se afirme el hecho, debidamente definido, con indicación de sus circunstancias precedentes, concomitantes y posteriores, lo que a su vez, es una exigencia del derecho de defensa, de la cosa juzgada y, en general, del principio de seguridad jurídica." (SAN MARTín CASTRO, César. Derecho Procesal Penal. Volumen I. Lima: Editora Jurídica GRIJLEY, 2000, pp. 298, 301, 302, 323, 327, 328).

7 El Tribunal Constitucional en el fundamento 30 de la sentencia en el Exp. N. ${ }^{\circ}$ 03987-2010-PHC/TC ha señalado "El principio acusatorio permite garantizar el derecho de defensa ya que sólo cuando existe un cargo concreto y específico la persona podrá defenderse".
} 
proceso está definida por la imputación ${ }^{8}$, y el objeto del debate por la oposición 9 . Definidos ambos aspectos de la contradicción -pretensión y oposiciónsurge como resultado un contradictorio pleno, y en consecuencia un debate cognoscitivo pleno de proposiciones contrapuestas.

El contradictorio - que da vida al proceso- solo puede configurarse sobre la base de una imputación concreta; por consiguiente, es reductivo estimar que ésta solo optimiza el derecho de defensa. Esto no es así, dado que la imputación concreta genera el contradictorio y, por tanto, configura la esencia misma del proceso.

La connotación jurídica de la imputación impone al juez el deber de verificar la realización del principio de legalidad; en efecto, el contradictorio se desarrolla sobre la base de una calificación jurídica adecuada que condiciona el orden del debate. Una imputación sin una calificación jurídica adecuada condiciona un contradictorio enervado y desordenado; se afecta la propia imputación y el derecho de defensa, vaciando su contenido esencial. Así, los juicios éticos, prejuicios y sospechas cubren el espacio de la ausente imputación, y se imposibilita su control objetivo y empírico. Por tanto, la imputación concreta cobra central importancia, de cara a un proceso contradictorio y cognitivo ${ }^{10}$.

\section{CONCEPTO}

Un concepto operativo de la imputación concreta, sin mayor pretensión teórica, permite definirla como el deber de la carga que tiene el Ministerio Público de imputar a una persona natural, un hecho punible ${ }^{11}$, afirmando proposiciones fácticas vinculadas a la realización de todos los elementos del tipo penal ${ }^{12}$. En efecto, el tipo penal es el referente normativo para la

\footnotetext{
8 Objeto de proceso es fijado o delimitado por la Fiscalía, a partir del cual se consolida y desarrollan los principios acusatorios y de contradicción, a diferencia del objeto del debate que se conforma con los hechos, pruebas y pretensiones de las demás partes procesales o de la resistencia hecha valer por el acusado. (Acuerdo Plenario 4-2007/CJ-116, fundamento 9).

9 En esa línea Montero Aroca: "El acusado nunca puede alterar el objeto del proceso, pero si puede ampliar el objeto del debate" (MONTERO AROCA, Juan. Op. Cit. pp. 129 -130).

10 La concepción cognitiva del proceso asegura dos objetivos políticos, uno la certeza controlable del juicio, y dos, la separación radical entre moral y derecho.

11 Con claridad magistral Kelsen precisa que: "La imputación es la vinculación entre un hecho (el objeto de la norma) y una persona (sujeto de la norma) realizada sobre la base de una norma (...)" (KELSEN, Hans. El Otro Kelsen. Primera Edición. México: Edit. UNAM -1989, p. 308.

12 El Tribunal Constitucional en el fundamento 30 de la sentencia emitida en el expediente 03987-2010 citando a Montón Redondo, ha señalado que por imputación se entiende en sentido material o amplio como: "la atribución, más o menos fundada, que se le hace a una persona de un acto presuntamente punible sin que haya de seguirse necesariamente acusación contra ella como su consecuencia" (Véase: MONTÓN REDONDO, Alberto. Derecho Jurisdiccional. Proceso Penal. Valencia: Tirant lo Blanch, 1998, p. 211).
} 
construcción de proposiciones fácticas ${ }^{13}$. Cada uno de los elementos del tipo exige su realización fáctica y ésta es presentada en la imputación penal con proposiciones fácticas ${ }^{14}$. Es necesario reiterar que la afirmación de hechos no es discrecional sino que está vinculada a la aplicación de la ley a los hechos propuestos, por ello, es una imputación legal. Si hay ausencia de proposiciones fácticas realizadoras de algún elemento del tipo, entonces, no se tiene una imputación ${ }^{15}$.

La imputación es la vinculación entre un hecho (el objeto de la norma) y una persona (sujeto de la norma) realizada sobre la base de una norma ${ }^{16}$; por consiguiente, la imputación se materializa con proposiciones fácticas que, por un lado, afirman un hecho punible; y por otro, imputan este hecho a un sujeto. La afirmación del hecho y su imputación están imbricadas; pero, para efectos prácticos es necesario destacar su diferencia. Las proposiciones fácticas vinculadas al hecho punible son predominantemente objetivas; en tanto que, las proposiciones fácticas que imputan el hecho a un sujeto tienen predominancia subjetiva; empero, se encuentran enlazadas.

Con frecuencia la imputación fiscal satura proposiciones fácticas del hecho punible, sin embargo, las proposiciones fácticas que vinculen al sujeto con el hecho son escasas o ausentes. La descripción extensa del hecho punible con débil atribución al sujeto, pervierte la imputación. La predominancia del debate solo respecto del hecho punible, enerva o anula el debate respecto de los elementos de la imputación que vinculen al imputado con el hecho punible, generando con ello indefensión. Es importante verificar exhaustivamente la concurrencia de ambos tipos de proposiciones fácticas; su ausencia o su generalidad dan lugar al desborde de la intuición -poco controlable- en desmedro de la cognición.

\footnotetext{
${ }^{13}$ Las afirmaciones son el medio necesario para introducir los hechos en el proceso. Entre hecho y afirmación se presenta un correlato necesario; en efecto, los hechos para ser incorporados en el proceso requieren de ser afirmados, y la afirmación no es sino afirmación de hechos. De cara a la actividad probatoria la única forma de probar los hechos es comprobando la veracidad de las afirmaciones, precisamente, de los hechos. Por consiguiente, es claro que el objeto de la prueba es el hecho y su afirmación.

14 Una proposición fáctica es una afirmación de hecho respecto de un caso concreto.

15 Precisa James Reátegui que: "el juicio de subsunción es un tema estudiado por el Derecho Penal material y el concepto de imputación es un tema de de Derecho Procesal Penal. El Juicio de tipicidad es contrastar que el hecho que está investigando es subsumible en un tipo penal, con lo cual, lo que busca dicho juicio es el marco típico de la conducta investigada. En cambio el concepto de imputación está ligada a la individualización de la conducta del sujeto, a la asignación de responsabilidad jurídico-penal a una persona humana...". Esta consideración nos parece correcta, sólo que indudablemente los dos conceptos están imbricados indisolublemente. (REÁTEGUi SÁNCHEZ, James. El Control Constitucional en la Etapa de Calificación del Proceso Penal. Primera Edición. Lima: Editorial Palestra, 2008, pp. 46 y 47).

16 Kelsen, Hans. El Otro Kelsen. Primera Edición. México: Edit UNAM, 1989, p. 308.
} 


\section{ESTRUCTURA DE LA IMPUTACIÓN CONCRETA}

Dos componentes completamente conjugados de la imputación son las proposiciones fácticas y su calificación jurídica. En efecto, las proposiciones fácticas de la imputación de un hecho punible no son libres o discrecionales, están vinculadas a la aplicación de la ley ${ }^{17}$, por ello una imputación concreta tiene la estructura de un tipo penal.

Analíticamente, el tipo penal es descompuesto en determinados elementos; sin embargo, el número de éstos no necesariamente tienen correspondencia con el número de proposiciones fácticas. En efecto, esto va a depender de la fortaleza o debilidad de la proposición fáctica ${ }^{18}$. Probablemente una proposición fuerte requerirá de una sola proposición fáctica para afirmar la realización de un elemento del tipo. Empero, si es débil, será necesaria la concurrencia de más de una proposición fáctica que configure la realización de un elemento del tipo.

En esta línea de pensamiento, las proposiciones fácticas configuradoras de elementos valorativos del tipo penal, por necesidad, serán más de una, porque lo valorativo exige una estimación conjunta de una pluralidad de proposiciones descriptivas. En tanto, que las proposiciones fácticas vinculadas a la realización de elementos descriptivos del tipo objetivo podrían ser únicas, dependiendo del caso concreto.

Los elementos de convicción son el tercer componente de la estructura de la imputación concreta. Cada uno de los componentes presenta problemas particulares que tienen que ser resueltos ${ }^{19}$.

\footnotetext{
17 “...es de tener presente que la promoción de la acción penal no es un acto discrecional del Fiscal está sujeta a requisitos legales..." (SAN MARTín CASTRO, César. Op. Cit. p. 367).

18 Señala Baytelman que “...las proposiciones fácticas pueden ser fuertes o débiles. Son más fuertes en la medida en que más satisfacen el elemento legal para el que fueron ofrecidas. Hay proposiciones fácticas que son tan fuertes, que ellas solas satisfacen el elemento completamente (...) la debilidad de una proposición fáctica (...) tiene que ver con su ineptitud para satisfacer el elemento legal para el que fue ofrecida" (Baytelman A, Andrés y Duce J, Mauricio. Litigación Penal y Juicio Oral y Prueba. Santiago de Chile: Edit. Universidad Diego Portales, 2004, p. 77).

19 A propósito de la estructura de la imputación el Tribunal Constitucional, en el expediente 03987-2010PHC/TC ha señalado "En resumen el derecho a ser informado de la imputación tiene tres elementos configuradores: i) La existencia de un hecho concreto y específico o la apariencia verosímil del mismo (STC N. ${ }^{\circ} 8125-2005-\mathrm{PHC} / \mathrm{TC}$ ); ii) La calificación jurídica (STC N. ${ }^{\circ}$ 06079-2008-PHC/TC); iii) La existencia de evidencia o de medios de convicción (STC N. ${ }^{\circ}$ s 5325-2006-PHC/TC; 9544-2006-PHC/TC)".
} 


\section{IMPUTACIÓN Y ELEMENTOS DE CONVICCIÓN}

Formalizar Investigación Preparatoria (FIP) presupone tener definido una imputación concreta ${ }^{20}$; cada una de las proposiciones fácticas deberá estar vinculada al hecho punible -que realizan los elementos del tipo- y su atribución a una persona. Pero la mera afirmación de proposiciones fácticas no satisface la necesidad de una imputación concreta. En efecto, afirmar un hecho punible y responsabilidad sin base indicativa, es flatus voci ${ }^{21}$. Si se tiene solo proposiciones afirmativas de la realización de un hecho, el imputado no puede defenderse materialmente de meras afirmaciones. Son precisamente los medios de convicción los que van a pautar o guiar la defensa del imputado, proponiendo la realización de actos de investigación para enervar el contenido de los medios de convicción.

Esta digresión entre proposiciones fácticas -edificación- e indicios reveladores -cimientos- posibilita el ejercicio idóneo del derecho de defensa; condiciona entonces un verdadero contradictorio y optimiza la defensa. Si no concurren indicios reveladores de la comisión de un delito no existe concreción de la imputación.

En definitiva no es suficiente la mera afirmación de proposiciones fácticas; es una condición necesaria pero no suficiente para configurar una imputación concreta. El concepto de imputación exige una base indicativa que sostengan las proposiciones fácticas. Conforme a esta exigencia se define a la imputación como "la atribución, más o menos fundada, que se le hace a una persona de un acto presuntamente punible sin que haya de seguirse necesariamente acusación contra ella como su consecuencia"22. La expresión "más o menos fundada", constituye una exigencia de concreción de cada proposición fáctica sobre la de base indicios reveladores de la comisión del delito e indicios reveladores que vinculen al imputado con este hecho. Por tanto, la imputación solo es concreta en tanto esté sostenida con elementos indicativos reveladores de la comisión del delito e indicios reveladores que vinculen al imputado con la realización del delito ${ }^{23}$.

${ }^{20}$ Art. 336 del NCPP, (1) “Si de la denuncia, del Informe Policial o de las Diligencias Preliminares que realizó, aparecen indicios reveladores de la existencia de un delito (...), que se ha individualizado al imputado (...) dispondrá la formalización y la continuación de la Investigación Preparatoria" 2.(b) "La Disposición de Formalización de Investigación Preparatoria contendrá: Los hechos y la tipificación específica

21 "Palabras que se lleva el viento".

22 Expediente 03987-2010. HC/TC citando a Montón Redondo, (Véase: MONTÓN Redondo, Alberto. Derecho Jurisdiccional. Proceso Penal. Valencia: Tirant lo Blanch, 1998, p. 211).

23 Empleemos una metáfora e imaginemos a la imputación como un edificio; los cimientos son la base de las edificaciones; en esa comparación los elementos de convicción son los cimientos de las proposiciones fácticas edificadas. Una edificación sin cimientos es endeble, provisional y no soportaría un temporal de intensidad 
Esta exigencia es menos intensa en la FIP, y es más rigurosa en el Control de Acusación (CA), como resultado del desarrollo del proceso propiamente de los actos de investigación ${ }^{24}$.

La imputación concreta ${ }^{25}$ exige para su configuración tres elementos: proposiciones fácticas, calificación jurídica y evidencia o medios de convicción. Es precisamente en la imbricación entre proposiciones fácticas y los medios de convicción donde puede realizarse el fundamento de aproximación razonable a la verdad y el programa de contención de la violencia punitiva. La unilateralidad de los que construyen proposiciones fácticas no vinculadas a elementos indiciarios tiene su esencia en el pragmatismo de la justicia negociada ${ }^{26}$.

La inicial práctica operativa de los jueces de Investigación Preparatoria fue verificar de manera compartimental primero las proposiciones fácticas y su calificación jurídica, luego los elementos de convicción; pero, que duda cabe, existe un nexo indisoluble entre proposiciones fácticas y los elementos de convicción; su verificación y control debe ser conjunta y no por separado; así cada proposición fáctica debe estar necesariamente vinculada con un elemento de convicción o indicio. De esta manera la imputación sí es concreta.

Es frecuente que la imputación contenga proposiciones fácticas con elementos de convicción, vinculadas a la realización del hecho punible; empero, son carentes de proposiciones fácticas con elementos de convicción que vinculan al imputado con el hecho. Obviamente en este último supuesto no existe imputación sino una mera sospecha; y, una

menor, dado que no tiene unos cimientos que los soporten; la mera presentación de proposiciones sin unos cimientos de convicción no generarían un contradictorio; es endeble, no es concreta.

Las edificaciones se construyen sobre la base de los cimientos; las proposiciones fácticas se edifican sobre la base de convicción; el rendimiento de estos determina el contenido de las proposiciones fácticas. Si se edifica proposiciones fácticas sin cimientos de convicción no se tiene una imputación concreta y, por tanto, estas proposiciones fácticas no vinculan al "imputado"; es mera afirmación.

${ }^{24}$ En ese orden de ideas, señala Reátegui Sánchez: “...en las instancias iniciales del procesamiento penal todavía no hay verdaderas pruebas incriminatorias, sino sólo meros indicios de la comisión de un hecho punible; entonces, no puede realizarse -o mejor exigirse- una imputación concreta, sino más bien de tipo genérica..." Sin embargo, no parece adecuado el empleo del término imputación genérica, en todo caso se trata de diferentes grados de concreción de la imputación. (REÁTEGUI SÁNCHEZ, James. Op. Cit., p. 17).

${ }^{25}$ La expresión de imputación concreta permite abarcar los elementos de convicción o los indicios reveladores, son los que concretan la imputación y permiten encontrar el nexo dialéctico entre las proposiciones fácticas calificadas jurídicamente y los elementos de convicción.

${ }^{26}$ Por el carácter dispositivo de la pretensión civil, su propuesta no está vinculada a la concurrencia de los elementos de convicción, en tanto que en la Imputación Penal es ajeno al principio dispositivo y que pone en riesgo los derechos fundamentales, deben estar premunidas de elementos indiciarios. 
Formalización de Investigación (FIP) sobre una base difusa es insostenible un proceso cognitivo.

\section{LA IMPUTACIÓN CONCRETA DEL DOLO}

La postulación de proposiciones fácticas vinculadas a la realización de los elementos del tipo subjetivo, corresponden a la subjetividad del agente y obviamente su reconstrucción se presenta con mucha dificultad, dado que humanamente no es posible penetrar en la subjetividad del agente y verificar su particular vivencia psicológica al momento de la realización del hecho delictivo $^{27}$.

El dolo como conocimiento y voluntad ${ }^{28}$ de la realización del hecho punible tiene que ser reconstruido con la imputación concreta. El dolo directo es compatible con un concepto psicológico descriptivo de la voluntad-voluntad descriptiva-; por tanto, la imputación exige proposiciones vinculadas al conocimiento y a la voluntad. Empero, el dolo indirecto y el dolo eventual solo es compatible con un concepto de voluntad normativa; así, será suficiente con imputar que el agente contaba con ciertos conocimientos al momento de realizar la conducta objetivamente típica para atribuirle un comportamiento doloso.

Independiente del problema anterior -voluntad descriptiva o normativa- se presenta el problema de imputar concretamente los conocimientos que tuvo el sujeto activo; se tienen dos respuestas: una de configuración realista y otra de configuración normativa.

La primera estima que los conocimientos requeridos por el dolo son datos de naturaleza psicológica; por consiguiente, se imputa una realidad que se encuentra en la psiquis del sujeto ${ }^{29}$; esta opción propende a una aproximación a la verdad que permita contener la violencia punitiva. Por otro lado, las "concepciones normativas" 30 señalan que no es posible averiguar el dolo

\footnotetext{
${ }^{27}$ En ese orden de ideas James Reátegui, señala que: "Es necesario no caer en el fácil error de considerar que sólo en la comprobación de la tipicidad objetiva el jurista del Derecho Penal debe recurrir a la subsunción. En efecto, también hay que subsumir los aspectos subjetivos del hecho. Por ejemplo el dolo o el ánimo de lucro. Aquí es necesario, lo mismo que el tipo objetivo, disponer de un concepto de "dolo" o "ánimo de lucro" (REÁtEGUI SÁNCHEZ, James, Op. cit., p. 47).

${ }^{28}$ El querer como criterio limitador permite distinguir el dolo de la imprudencia, la cuestión se complica cuando se trata de un dolo de segundo grado o de consecuencia necesarias y el dolo eventual.

${ }^{29}$ Los autores que adoptan esta propuesta la denominan concepción psicológica.

30 Ragues I Valles, Ramón. El dolo y su prueba en el Proceso Penal. Prólogo de Jesús María Silva Sánchez, Editorial J.M. Bosch Editor, 1999.
} 
en las concretas vivencias psicológicas del sujeto activo, por consiguiente, recurren a criterios normativos de determinación del dolo; se atribuye o imputa un determinado conocimiento a un sujeto, y con ello el dolo, pero empleándose criterios distintos a la verificación empírica de datos psicológicos. Sin embargo, desde esa óptica normativa se enerva la posibilidad de contener la violencia punitiva; y, probablemente dará lugar a que se atribuya dolo donde no existe dolo $^{31}$.

Corresponde entonces presentar proposiciones fácticas de directo contenido subjetivo, pero, a su vez necesariamente proposiciones objetivas indicativas de un hecho subjetivo indicado -la intencionalidad- que permitan inferir inductivamente la intencionalidad del sujeto activo ${ }^{32}$. Nótese que no se renuncia a la aproximación razonable a la verdad; pero no se postula ingenuamente solo proposiciones fácticas de directo contenido subjetivo, sino además proposiciones objetivas que sean signos inequívocos de una intencionalidad ${ }^{33}$.

El Ministerio Público tiene el deber de la carga de afirmar proposiciones fácticas de una realidad psíquica, y el deber de la carga de probar éstas. Las experiencias psíquicas no pueden probarse de manera directa, carece de sentido pretender su probanza de manera directa. Por ello, la lógica indiciaría cobra capital importancia para probar realidades subjetivas; en efecto, las proposiciones fácticas -indicativos- tienen que ser probados para inferir intencionalidad.

Una postura congrua con un programa de contención de la violencia punitiva no puede renunciar al hecho subjetivo, como objeto de control. Estas pueden armonizar con reglas de sentido social que operen como correctivos de una imputación subjetiva -realidad subjetiva-.

No obstante lo afirmado, algunas veces se pretende la prueba directa de proposiciones fácticas de hechos subjetivos; sin embargo, no se ha puesto mucha atención a las proposiciones objetivas indicativas que posibilitarían

\footnotetext{
31 El caso utopía en el Perú y el caso Cro magnon en Argentina, son claras manifestaciones de ello.

32 Un concepto coherente e impecable teóricamente como el dolo, sin embargo, operativamente no sirva para nada.

33 Julio César Santa Cruz, realiza una importante distinción entre: a) imputación fáctica: en la que sí cabe imputar directamente proposiciones fácticas de directo contenido subjetivo; b) imputación conviccional (teoría probatoria) en la que habría que indicar los hechos indiciarios del dolo a través de proposiciones fácticas; de estos hechos indiciarios, a través de determinadas reglas de la experiencia, ciencia o técnica se colegiría el dolo.
} 
inferir el dolo del agente. Probar directamente las proposiciones fácticas subjetivas, es una exigencia de imposible cumplimiento dado que el hecho psíquico solo se presenta en la subjetividad del sujeto. Su exigencia de probanza directa puede generar lagunas de impunidad y, en el contexto de la reforma, puede ser indebidamente aprovechada por ausencia de proposiciones objetivas indicativas de la subjetividad del agente.

\section{OPERATIVIDAD FUNCIONAL: ETAPAS}

La imputación concreta configura el proceso, pero a su vez tiene funciones específicas en cada una de las etapas del proceso que orientan la actividad de los sujetos procesales; es el punto de referencia necesario que define y delimita el objeto de cada una de las etapas -Diligencias Preliminares, Investigación Preparatoria, Etapa Intermedia y Juzgamiento- ${ }^{34}$.

Las Diligencias Preliminares ${ }^{35}$ (DP) tienen como objeto definir los contornos de la imputación concreta y para ello tienen por finalidad realizar los actos urgentes e inaplazables destinados a determinar si han tenido lugar los hechos objeto de conocimiento y su delictuosidad, así como asegurar los elementos materiales de su comisión. Su objeto es pues definir la estructura de la imputación concreta: hechos, calificación jurídica y medios de convicción. Si concurren estos tres componentes entonces el Ministerio Público tiene una imputación concreta y; por tanto, corresponde formalizar y continuar con la Investigación Preparatoria (FIP).

Una práctica -contra legem- de la fiscalía ha desnaturalizado esta finalidad ${ }^{36}$; pues, no obstante existir una imputación concreta se dispone, por regla general, Diligencias Preliminares. Se ha pervertido su objeto y finalidad; su recurrencia acarrea consecuencias negativas, enerva el contradictorio con sensible afectación del derecho de defensa, y degenera en dilación. Peor aún, ordenar Diligencias Preliminares policiales sin estrategia, constituye una práctica formularia que anquilosa la investigación. Si se tiene una imputación concreta, entonces, su consecuencia es la Formalización de la Investigación Preparatoria (FIP).

\footnotetext{
${ }^{34}$ Ciertamente el control de imputación es una actividad dinámica que se realiza en todo el desenvolvimiento del proceso.

35 Art. $330^{\circ} .2$ del NCPP.

36 Art. 330.2 del NCPP.- "Las diligencias preliminares tienen por finalidad inmediata realizar los actos urgentes e inaplazables destinados a determinar si han tenido lugar los hechos objeto de conocimiento y su delictuosidad, así asegurar los elementos materiales de su comisión, individualizar a las personas involucradas en su comisión, incluyendo a los agraviados, y dentro de los límites de la ley, asegurarlas debidamente".
} 
Si de la denuncia, del informe policial o de las Diligencias Preliminares (DP) que realizó aparecen indicios reveladores de la existencia de un delito -imputación concreta -, entonces el fiscal dispondrá la Formalización de la Investigación Preparatoria $^{37}$ (FIP) y ésta debe contener los hechos y la tipificación específica correspondiente ${ }^{38}$.

La imputación concreta determina el objeto de la investigación y su finalidad, por consiguiente, la pertinencia y utilidad de los actos de investigación propuestos por las partes para el esclarecimiento de los hechos. Es sobre la base de esta imputación que las partes puede controlar la imputación, oponer sus medios de defensa ${ }^{39}$ y ofrecer la realización de actos de investigación para enervar la imputación. Si no se tiene definida la imputación esta etapa degenera en una reproducción de ritualismos anquilosantes sin finalidad; una investigación ciega, sorda, torpe e inhumana siempre exacerba un latente autoritarismo de sus operadores ${ }^{40}$. La reducción de la investigación a un mero expediente sin una imputación concreta esconde el drama humano generado por el conflicto delictivo.

Cualquier audiencia previa al juicio oral - prisión preventiva, excepciones, cuestión previa, etc.- esta condicionada por la imputación concreta formalizada. El debate en una excepción o una prisión preventiva gira sobre la base de la imputación concreta definida en la Formalización de la Investigación Preparatoria (FIP). Determina el objeto del debate de las audiencias previas al juicio oral pues es su parámetro de congruencia. Pretender incorporar información diferente a la imputación concreta es emboscar a la otra parte y, sorprender al Juez. La incorporación de una base fáctica distinta solo puede realizarse con una ampliación de la Formalización de la Investigación Preparatoria (FIP), nunca en el accesorio de un requerimiento de prisión preventiva $u$ otro tipo de audiencia previa.

Concluida la investigación, el Juez -en la Etapa Intermedia (EI) - realizará un exhaustivo control de la imputación, verificará su base fáctica, la calificación jurídica y los elementos de convicción suficientes para decidir el enjuiciamiento del imputado. Los medios de defensa que se opongan en esta etapa también tienen su punto de referencia en la imputación concreta.

\footnotetext{
${ }^{37}$ Artículo $336^{\circ}$ numeral 1 del NCPP.

38 Así se encuentra previsto en el literal " $b$ " numeral 2 del artículo $336^{\circ}$ del NCPP.

39 Un típico medio de defensa que cuestiona la imputación, es la excepción de improcedencia de acción por medio del cual se cuestiona la calificación jurídica del fáctico propuesto.

${ }^{40}$ La práctica autoritaria tenía su cobertura en el secreto que suponía el expediente.
} 
En el enjuiciamiento (JO), de entrada, la imputación concreta delimita el objeto del proceso; y, con la resistencia, el objeto del debate. Sobre este eje se desarrolla el contradictorio de toda la actividad probatoria. Sirve como parámetro de pertinencia conducencia y utilidad en la dirección judicial del debate y pauta la litigación oral de los adversarios. Finalmente en la etapa decisoria, la imputación concreta es el elemento de referencia para verificar el principio de congruencia procesal entre acusación y sentencia. En efecto, la determinación concreta de la imputación de un hecho punible afecta de manera decidida los fundamentos de hecho y de derecho con los que el juez justifica sus decisiones.

\section{PERVERSIÓN DE LA IMPUTACIÓN CONCRETA}

Frecuentes prácticas en la propuesta de la imputación concreta han pervertido su función. Anotemos algunas.

Se pervierte la imputación cuando, a pesar de existir información valiosa en los actos de investigación, las proposiciones fácticas no son construidas sobre la base de esta información. Las partes pueden tener conocimiento de esa información por haber accedido al expediente, pero, esto no exime al Ministerio Público del deber de construir proposiciones fácticas para materializar una imputación concreta. No se realiza la operación de sintetizar la información investigativa -construyendo proposiciones fácticas- sino que se asume erradamente que es suficiente con la información dispersa en la carpeta fiscal. Esto es erróneo.

La débil presencia de proposiciones fácticas puntualizadas con base en la investigación genera en los jueces el apremio de recurrir al expediente para obtener información por defecto o ausencia de las proposiciones fácticas. Determina a que sean los jueces quienes construyan proposiciones fácticas para fundamentar sus decisiones y con ello el retorno sin ambages al inquisitivo, con jueces haciendo las veces de fiscales. El efecto más pernicioso es la anulación del contradictorio, pues solo con proposiciones fácticas se puede materializar el contradictorio y optimizar el ejercicio de la defensa. Si no hay imputación, no hay defensa, por más que la información se encuentre en la carpeta fiscal. Con todo ello se resiente seriamente el principio acusatorio y el carácter cognitivo del proceso y da lugar a un ritual de sospecha y de atribuciones éticas.

El trabajo fiscal se vertebra sobre la base de construir proposiciones fácticas, sintetizando la información obtenida con los actos de investigación -conforme a un enfoque jurídico-. Esta es precisamente su labor central, compleja 
pero indispensable. De nada sirve acopiar información sin un norte. Esa información, es el insumo que se sintetiza en proposiciones fácticas calificadas jurídicamente que, a su vez, orientan o reorientan la actividad investigativa, buscando nueva información. La imputación concreta es el resultado de esa tensión dialéctica entre actividad investigativa y proposiciones fácticas. Si el operador fiscal no es consciente de esta dinámica, realizará una labor unilateral de acopio cuantitativo de información, sin proyección estratégica en la obtención de información de calidad.

La falta de destreza en la construcción de proposiciones fácticas, da lugar a que se realicen imputaciones con errados juicios de tipicidad, no obstante que de los elementos indiciarios se tiene base fáctica para construir proposiciones fácticas con un correctojuicio de tipicidad. El Juez de Investigación Preparatoria (JIP) no tiene atribuciones para controlar que el fiscal construya proposiciones fácticas con determinada información de los actos de investigación, solo controla la calificación jurídica de las proposiciones fácticas propuesta por la fiscalía. Sería contrario a su rol constitucional ordenar u orientar la construcción de proposiciones fácticas en determinado sentido jurídico. Por tanto, el desarrollo de destrezas en la construcción de proposiciones fácticas sobre la base de la actividad investigativa es una tarea pendiente y de urgencia que corresponde a la fiscalía.

Otra perversión se presenta cuando la imputación contiene proposiciones fácticas vinculadas a la realización del hecho punible, pero es carente de proposiciones fácticas que vinculen al imputado; otras veces se propone proposiciones genéricas no concretadas en indicios reveladores. Obviamente en ambos supuestos no existe imputación y da lugar a la sospecha como fundamento. Una formalización de imputación sobre base difusa es insostenible en un proceso cognitivo, se anula éste carácter y deviene en un escenario de linchamiento ético; $y$, el debate moral se impone, saturando el escenario de la audiencia con prejuicios de los operadores jurídicos.

Se impone una activa labor judicial en el control de imputación ${ }^{41}$, verificando la existencia en el proceso de una imputación con indicios reveladores de la comisión de un delito y de la intervención del imputado ${ }^{42}$. Es una necesidad

\footnotetext{
41 "El Juez penal tiene un control de legalidad sobre el ejercicio de la acción penal, por lo que el procesamiento de quien resulte emplazado por el Fiscal requiere autorización o decisión judicial. Sin embargo, esa autorización o resolución judicial no es automática, el Juez no actúa como simple receptor del procesamiento dispuesto por el Ministerio Público. En su misión de garante de los derechos individuales de las personas, especialmente de quienes están sujetas a una persecución penal, el Juez debe evaluar si la promoción de la acción penal se amolda a los requisitos que establece la ley procesal, es decir, le corresponde un papel de defensor del ordenamiento jurídico..." (SAN MARTín CASTRO, César. Op. Cit., p. 367).

42 Art. $336^{\circ} .1 .4$ del NCPP.
} 
de lege ferenda una audiencia de control de imputación luego de Formalizada la investigación preparatoria (FIP); y, en el Control de Acusación (CA) una exhaustiva verificación -ajeno a un control formulista- de una causa probable que justifique el desenvolvimiento de un juicio oral ${ }^{43}$.

Se pervierte la imputación concreta cuando se presenta excesivas proposiciones fácticas no vinculadas al hecho constitutivo, sino a las circunstancias precedentes, concomitantes y posteriores ${ }^{44}$. Esta exuberancia de circunstancias rodea o circundan generalmente débiles proposiciones fácticas del hecho constitutivo. El exceso de proposiciones fácticas circundantes esconde la débil presencia de proposiciones fácticas del hecho constitutivo.

Una técnica operativa para construir una imputación exige elaborar en primer orden -como núcleo- las proposiciones fácticas de la imputación; solo después las proposiciones fácticas que configuran las circunstancias ${ }^{45}$. Primero la determinación de la imputación -hecho constitutivo- y solo como consecuencia las circunstancias; éstas por sí solas no tienen base. Por consiguiente, el Ministerio Público centrará arduamente su labor en la imputación constitutiva de los elementos del tipo; solo luego construirá las proposiciones fácticas que configuran las circunstancias. Se evita así, el exceso de circunstancias en desmedro del hecho constitutivo.

La concurrencia de circunstancias de contexto y con débiles proposiciones de un hecho constitutivo determina que gane terreno la eticidad del proceso en desmedro del carácter cognitivo de éste; por tanto, la brega por la presentación de proposiciones fácticas esta directamente vinculada con la caracterización cognoscitiva del proceso.

\section{FORMULISMO E IMPUTACIÓN}

El formulismo, otra perversión de la imputación concreta, se expresa en la utilización de formatos que al pretender cargarlos da lugar a contenido reiterativo. La acusación es exuberante, pero con débil contenido del hecho punible. El estilo forense no puede ajustarse al cumplimiento del formato de la acusación; puede ser distinto y hacer un uso residual del formulario. La verificación exhaustiva del cumplimiento del contenido por rigurosos rubros formales constituye una práctica formularía que anula la construcción de una imputación conforme a las particularidades del caso.

El estrecho rigor del formato condiciona severas confusiones, así la imputación -hecho constitutivo- es disgregada de manera inarticulada, en circunstancias 
precedentes concomitantes y posteriores. El formalismo extremo degenera en un descuartizamiento de la imputación. Esta desagregación de la imputación es consecuencia directa de la utilización del formato, éste exige que la acusación contenga las circunstancias precedentes concomitantes y posteriores al hecho constitutivo $\mathrm{y}$, ante la ausencia de las circunstancias, para satisfacer los requerimientos del formato ${ }^{46}$, se descompone el hecho delictivo en "circunstancias".

Este formulismo, en apariencia facilita el trabajo fiscal, no permite una práctica eficiente de control de la imputación concreta. Así la robótica práctica formularia debe ser criticada y combatida pues imposibilita la reflexión y torna ineficiente el control de la imputación. Además, no es inocuo, las defensas formalistas utilizan este formato como un esquema de evaluación y es aprovechado para cuestionar la ausencia de proposiciones fácticas constitutivas del tipo, no obstante encontrarse éstas bajo la nominación de circunstancias.

Lo importante es la concurrencia de la imputación fáctica con proposiciones fácticas realizadoras de los elementos del tipo, independientemente de la nomenclatura formularia que se emplee. Es claro que la imputación fáctica -hecho punible- es el núcleo constitutivo de la imputación y que las circunstancias rodean este hecho. Son bases fácticas distintas, unas son el núcleo y las otras son periféricas al núcleo, las primeras son esenciales, las segundas no son esenciales. Las circunstancias solo deben ser postuladas en tanto sean generadoras de consecuencias jurídicas ${ }^{47}$. Esta perspectiva procesal permite un control eficiente de los requisitos de fondo de la imputación penal, porque nos permite focalizar el problema.

Si el fáctico constitutivo del hecho punible se encuentren bajo otra denominación formularia, ello no supone ausencia de imputación. Una cosa es que éstas no existan y otra que los hayan desarrollado en otros rubros ${ }^{48}$;

\footnotetext{
${ }^{43}$ Art. $344^{\circ}$.2.d. del NCPP.

44 El Juez de control de acusación vería devolver la acusación a fin de que el Fiscal diferencia nítidamente los Hechos de sus Circunstancias.

${ }^{45}$ La imputación sería el cuerpo sólido que golpea las aguas tranquilas y las circunstancias el efecto de las ondas que circundan el golpe de la imputación.

${ }^{46}$ Los formatos que se utilizan para presentar la acusación constituyen una especie de formularios más o menos ajustada a exigencias normativas $\left(349^{\circ} \mathrm{CPP}\right)$, pero no vincula normativamente.

47 Normalmente estos efectos están vinculados a la individualización de la pena.

${ }^{48}$ Con acierto señala Julio César Santa Cruz que: Debe exigirse al Fiscal que bajo el rubro de Hechos Atribuidos presente la todos los hechos que imputa; pues de esto es de lo que debe defenderse el investigado o acusado.esta exigencia debe hacerse tanto en relación a la Disposición de formalización de la IP como a la Acusación.
} 
por tanto, no es un supuesto de sobreseimiento ${ }^{49}$, entonces corresponde al Juez disponer su ordenación devolviendo la acusación ${ }^{50}$.

Precisando, la imputación concreta es presupuesto del contradictorio, configura el proceso; sin él simplemente no existe proceso, es eje central del proceso, determina el carácter cognitivo del proceso, en cualquiera de sus etapas. Si la imputación es defectuosa entonces incide directamente en la configuración defectuosa del proceso, y degenera su carácter cognitivo en uno de sospecha y prejuicios. Por esa razón los cuestionamientos a la perversión de la imputación apuntan a generar buenas prácticas en perspectiva de un auténtico proceso centralmente cognitivo y por tanto controlable. El abordaje de la imputación concreta y los problemas de su calificación jurídica, merecerán un enfoque independiente.

De lo contrario, la defensa tendría que defenderse de cualquier afirmación Fiscal que se encuentre a lo largo de las frecuentemente numerosas páginas, lo que introduce un serio escollo al ejercicio de la defensa, que se genera únicamente por inoperancia del Fiscal. No es legítimo cargar al imputado los defectos de preparación del los operadores del sistema penal.

49 Art. $344^{\circ}$ del NCPP.

50 Art. $352^{\circ} .2$ del NCPP. 